\title{
Análise da expansão urbana no entorno da Lagoa Grande e Lagoa da Tabua no município de Feira de Santana-BA a partir de série histórica de imagens Landsat MSS, TM e ETM
}

\author{
Analysis of urban expansion in the vicinity of Lagoa Grande and Lagoa da Tabua in Feira de Santana-BA from \\ historical series of Landsat MSS, TM and ETM images
}

\author{
Alarcon Matos de Oliveira ${ }^{1}$ \\ Vivian de Oliveira Fernandes ${ }^{2}$ \\ Mauro José Alixandrini Junior ${ }^{2}$ \\ Patrícia Lustosa Brito ${ }^{2}$
}

\author{
${ }^{1}$ Faculdade de Filosofia Letras e Ciências Humanas LASERE - Laboratório de Aerofotografia e Sensoriamento Remoto \\ Universidade de São Paulo USP - Avenida Prof. Lineu Prestes, 338. \\ Cidade Universitária. CEP: 05508-080 São Paulo SP. \\ ${ }^{2}$ Escola Politécnica - Departamento de Transporte, Universidade Federal da Bahia - UFBA - \\ Aristides Novis 2 - Federação 40210630 - Salvador, BA - Brasil
}

\begin{abstract}
RESUMO - É crescente a necessidade de proteção dos recursos hídricos, em especial os mananciais urbanos, uma vez que são constantemente "invadidos" pela expansão desordenada das cidades. Nesse sentido, as ferramentas de análise espacial, o Sensoriamento Remoto e a Cartografia, constituem um poderoso instrumento de avaliação dos impactos ambientais. Tais ferramentas foram exploradas nesse trabalho, cujo objetivo é realizar mapeamento multi-temporal do entorno da Lagoa Grande e Lagoa da Tabua, município de Feira de Santana/BA, no período de 1975 a 2008 . A escolha desse período deve-se ao fato do grande crescimento populacional, ocasionado pela industrialização do município. Para realização do trabalho foram utilizadas imagens de satélites, dos sensores MSS, TM do programa LANDSAT. Os procedimentos técnicos adotados na construção desse trabalho consistiram nas seguintes etapas: georreferenciamento das imagens; com aplicação de técnicas de realce e contraste; e classificação supervisionada, um método clássico de processamento, dando foco maior na avaliação das imagens empregadas (sazonalidade da região) e ao correlacionamento do impacto ambiental com os resultados de estatísticas oficiais. Foi possível, através deste método, identificar alguns indicadores de desequilíbrio ambiental, como por exemplo, o avanço do espaço urbano implicando em sedimentação da Lagoa da Tabua, e na presença de Taboa, de vegetação aquática comum em áreas muito poluídas na Lagoa Grande.
\end{abstract}

Palavras-chave: Mananciais urbanos, classificação de imagem, cobertura da terra

\begin{abstract}
The need for protection of the water resources, in especial the urban water resources, rises each day, along with the disordered expansion of the cities. For that reason, the tools of spatial analysis, the Remote Sensing and Cartography that came up as a powerful evaluative instrument of the environmental impacts. Based on this understanding that the objective of that work is to accomplish a multi-temporal mapping at the surrounding of Grande Lagoon and Tabua Lagoon; in the period from 1975 to 2008, the choice of that period is due to the fact of the population boom, caused by the industrialization of the municipal district. For the accomplishment of this work it will be used the available satellite images. It will be used the sensors MSS, TM and ETM. The adopted technical procedures, in the construction of that work will consist in the following stages. The geo-referenced of images, applying the enhancement and contrast techniques, Supervised Classification. A classic method for processing giving greater focus the evaluation of the images(seasonality of the region) and the correlating environmental impact with official statistics. It was possible by this method to identify some indicators of environmental imbalance, such as the advancement of urban space implying sedimentation pond of the Tabua, and the presence of cattail, aquatic vegetation common in heavily polluted areas in the Grande Lagoon.
\end{abstract}

Keywords: Urban watersheds, image classification, land cover

\section{INTRODUÇÃ̃o}

A água é imprescindível na manutenção da vida terrestre, uma vez que a mesma mantém os seres vivos, regula o clima, dá forma ao relevo, além de diluir resíduos e poluentes, sendo reciclada pelo ciclo hidrológico. Segundo Miller (2007), hidrosfera corresponde a $71 \%$ da 
superfície terrestre, porém 97,4\% dessas águas estão localizadas nos oceanos e lagos salinos. Ou seja, apenas 2,6\% das águas são classificadas como água doce. Assim surge a necessidade crescente de proteção aos recursos hídricos, sendo que essa proteção se concretizará efetivamente à medida que sejam realizados estudos científicos a respeito dos recursos hídricos.

Grandes avanços na área da computação, no processamento de imagens e nos sistemas sensores, cada vez com mais resolução espaciais mais apurados e gama maior de bandas multiespectrais, vêm expandindo o uso das técnicas de Sensoriamento Remoto. No entanto, técnicas e sensores considerados tradicionais permanecem de grande valia e continuam permitindo o desenvolvimento de importantes estudos ambientais como o aqui apresentado.

Dessa forma, com base em imagens de 1975 e de 2008 do programa Landsat, considerado nos dias atuais de baixa resolução para estudos urbanos, e com uso da técnica de classificação supervisionada, realizou-se um estudo sobre a ação antrópica nas lagoas urbanas do município de Feira de Santana - BA.

O presente artigo apresenta a técnica utilizada e os resultados da análise temporal do avanço da ocupação urbana sobre a Lagoa da Tabua e Lagoa Grande, ambas situadas na área urbana do município.

\section{LOCALIZAÇÃO DA ÁREA DE ESTUDO}

O município de Feira de Santana está localizado no Estado da Bahia (Fig. 1), na Região Econômica do Paraguaçu, território de identidade Portal do Sertão, com área de $1.350 \mathrm{~km}^{2}$, situado cerca de $105 \mathrm{~km}$ a noroeste (NW) da cidade de Salvador, capital do estado baiano, tendo como retângulo envolvente as coordenadas geográficas $12^{\circ} 09^{\prime}$ e $12^{\circ} 20^{\prime}$, na latitude Sul e $38^{\circ} 53^{\prime}$ e $39^{\circ} 07^{\prime}$, de longitude Oeste. A população atual é de aproximadamente 550.000 habitantes.

\subsection{Lagoa Grande}

A lagoa Grande (Fig. 3A) está localizada na região leste da cidade (Fig. 2), e possui este nome por ter sido uma das maiores lagoas situado no perímetro urbano nos anos cinquenta. Neste período histórico do município, a Lagoa da Tabua era considerada uma lagoa rural e Feira de Santana tinha a captação de água para consumo humano realizado nesta lagoa. Segundo relatos históricos já se iniciavam as primeiras invasões no entorno da lagoa.

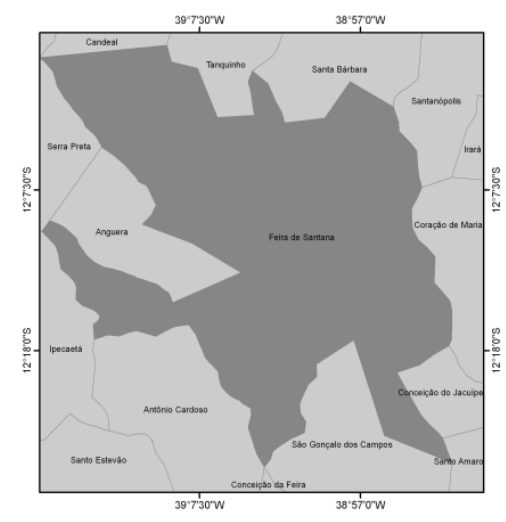

Mapa de Localização de
Feira de Santana

Figura 1 - Localização referente ao município de Feira de Santana.

\subsection{Lagoa da Tabua}

Localizada ao Norte da cidade de Feira de Santana (Fig. 2), a Lagoa da Tabua (Fig. 3B) possui esse nome devido ao fato de sua vegetação original possuir vários exemplares de Typha domingensis. É uma das maiores lagoas do município. No final da década de 80 (oitenta) e início dos anos 90 (noventa), este corpo d'água possuía várias espécies de peixes como fonte de extração de pesca e lazer de vários moradores da região. Esta lagoa é uma das nascentes do Rio Pojuca, contudo, devido ao avanço do espaço urbano, a mesma possui dificuldade em conseguir manter sua lâmina de água.

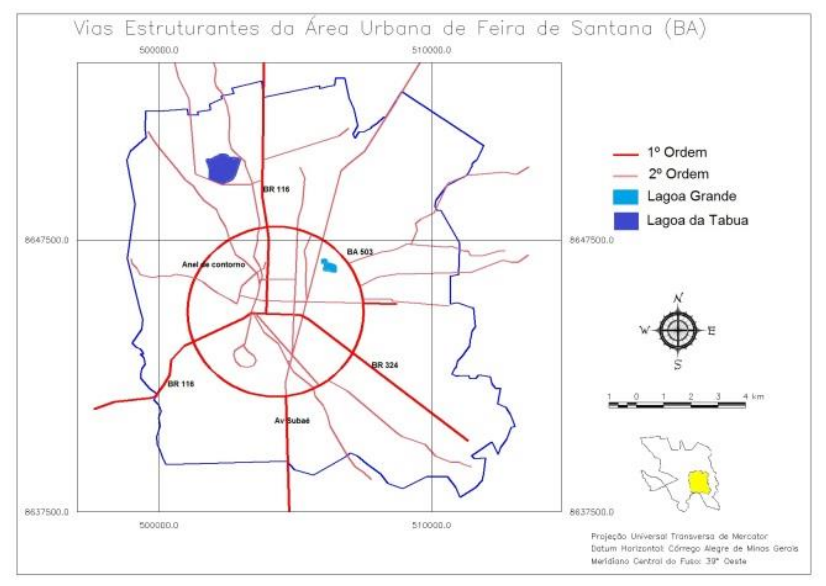

Figura 2 - Área Urbana do Município de Feira de Santana, na ampliação, em destaque as Lagoas: Grande e da Tabua.

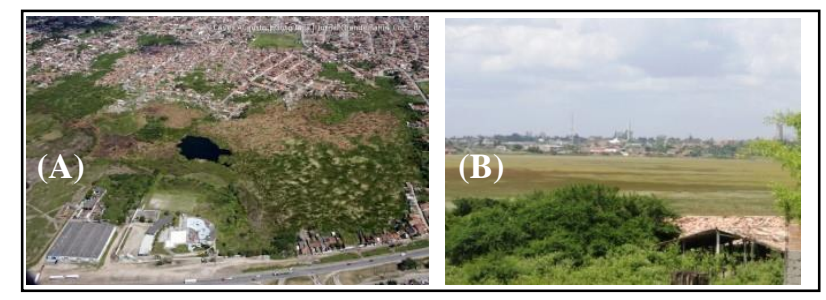

Figura 3 - Imagens panorâmicas das lagoas: (A) Lagoa Grande e (B) Lagoa da Tabua.(Fonte: Jornal Grande Bahia) 


\section{MATERIAIS E MÉTODO}

\subsection{Materiais}

Foram utilizadas as imagens Landsat 2 Sensor MSS do ano 1975, Imagens Landsat 5 Sensor TM do ano de 2008 e software de processamento digital de imagens de Sensoriamento Remoto, softwares disponíveis no Laboratório de Geomensura da Universidade Federal da Bahia.

\subsection{Procedimentos Técnicos}

Utilizou-se neste trabalho, o método clássico de processamento Digital de imagens e o foco dado na seleção das imagens, foram orientadas pelo regime hídrico característico da área estudada. Para a etapa de análise dos resultados, onde foram exploradas relações dos produtos oriundos dos processamentos com variáveis ambientais importantes para as lagoas. No método de processamento temos as seguintes etapas: Georreferenciamento das imagens e Classificação supervisionada descritos a seguir.

\subsubsection{Georreferenciamento}

Entende-se por georreferenciamento ou registro de uma imagem, um conjunto de operações métricas que modifica ou altera sua geometria de maneira a ajustá-la a um sistema de coordenadas considerado como referência (PHILLIPS; SWAIN, 1988). Este procedimento pode ser realizado por uma equação polinomial, cujos coeficientes são calculados a partir dos pontos de controle. Esses pontos devem ser identificáveis, tanto na imagem base como na imagem a ajustar e deve-se buscar uma distribuição espacial uniforme desses pontos (RICHARDS; JIA, 2006). A equação correlaciona as coordenadas da imagem (linha, coluna) e do sistema de referência cartográfico definido.

Ao se aplicar uma função polinomial para transformar a geometria de uma imagem para um sistema de coordenadas planas ou geográficas, serão minimizados alguns erros geométricos. Porém, a precisão do registro deve ser verificada. Isto é possível aumentando o número de graus de liberdade na determinação desses parâmetros. Estes erros podem ser mensurados através da seguinte equação (RICHARDS, 1993; MATHER, 1987):

$$
R M S=\frac{\sum \sqrt{\left(X_{B i}-X_{T i}\right)^{2}+\left(Y_{B i}-Y_{T i}\right)^{2}}}{n},
$$

onde, RMS é o Erro Médio Quadrático, (Root Mean Square Error); $X_{B}$ e $Y_{B}$ coordenadas dos pontos na imagem Base; $X_{T}$ e $Y_{T}$ coordenadas dos pontos na imagem a registrar transformados pela função polinomial definida e os pares de pontos variam de $i=1,2, \ldots n$.
O RMS eq. (1) não é uma medida de posicionamento absoluto de uma imagem, mas um indicador de consistência na distribuição dos pontos. Se um erro sistemático de vários pixels for cometido sempre na mesma direção, durante a coleta dos pontos, ele não será evidenciado no RMS. Os valores do RMS podem variar bastante em função da acurácia de base usada como referência e da qualidade da coleta dos pontos de controle. Crosta (1993) firma ser recomendável que a margem de erro fique em torno de \pm 1 , ou seja, RMS não ultrapasse a dimensão de um pixel da imagem a ser registrada. A qualidade do resultado pode ser melhor verificada pela sobreposição de elementos vetorizados de uma base cartográfica, caso disponha desse tipo de material. Neste caso, não deve haver desvios significativos das feições observadas na imagem em relação aos mesmos elementos presentes nas cartas usadas como referência.

Vale ressaltar que na maior parte dos casos o georreferenciamento de imagem Landsat obtém resultados satisfatórios com transformação polinomial de primeiro grau, visto que as imagens já sofreram correções geométricas básicas necessitando apenas de uma rotação e uma translação para ajustamento ao sistema cartográfico de referência (CROSTA, 1993).

Para a efetivação do georreferenciamento neste trabalho foi preciso realizar as seguintes etapas: recorte da cena, reamostragem e registro. Os resultados são descritos em detalhes a seguir.

\subsubsection{Reamostragem}

Entende-se por reamostragem um método estatístico que usa a distribuição de probabilidade assumida, todavia, ela calcula distribuição empírica de estatística estimada. Com isso são criadas múltiplas amostras. Esse procedimento estatístico tem a função, quando aplicada ao Sensoriamento Remoto, de reduzir ou aumentar a resolução espacial de uma imagem (LILLESAND; KIEFER, 2000; SCHOWENGERDT, 2007).

Neste trabalho adotou-se o princípio da superresolução que se extrapola a resolução espacial das imagens digitais e, por consequente, na melhoria da qualidade visual das mesmas. Adotou-se como método da super-resolução o realce de detalhes existentes na imagem. Esta operação amplia as altas-frequências através da técnica de restauração e interpolação adaptativa (ALIXANDRINI, 2010; FERNANDES et al., 2011). Sendo assim os filtros adaptativos amplificam os componentes de alta frequência atenuada no processo da reamostragem. As técnicas de reamostragem são importantes em diversas operações do processamento digital de imagens, destacando-se correção geométrica, registro de imagens de igual ou diferente resolução espacial; com o objetivo de aumentar a resolução espacial de uma imagem; (LILLESAND; KIEFER, 2000).

Com esta técnica foi possível aumentar a resolução espacial do satélite Landsat 2 sensor MSS de 80 x 80 metros para 30 × 30 metros. Esta etapa se faz necessária, pois este trabalho é multi-temporal e a outra imagens adotada é do satélite Landsat 5 sensor TM que possui 
resolução espacial de 30 × 30 metros, portanto para que estas imagens sejam registradas entre si é preciso que ambas estejam na mesma resolução espacial.

\subsubsection{Correção geométrica}

Correção geométrica de imagem compreende a transformação geométrica que correlaciona as coordenadas de imagem (linha $x$ coluna) com coordenadas de um sistema de referência. No entanto, as imagens utilizadas neste trabalho foram obtidas gratuitamente no site do INPE e encontram-se georreferenciadas com as seguintes características: coordenadas plano retangulares do sistema de projeção UTM, zona 24 no hemisfério sul e seu Datum WGS 84.

\subsubsection{Registro}

Para registrar as imagens utilizou-se como base a imagem Landsat 5 sensor TM do ano de 2008, optou-se por esta imagem por ser a imagem mais recente da série histórica adotada. Para se registrar uma imagem $x$ imagem, ou seja, utilizar uma imagem com base e outra imagem para ser registrada pela imagem base, são necessários uma quantidade mínima de 3 pontos de controle no entanto foram adotados 6 pontos para determinar a precisão da determinação dos parâmetros da função. Os pontos de controle foram coletados preferencialmente em cruzamento de estradas e cruzamentos de rodovias leito de rio; a escolha destes pontos se deve ao fato de que estas áreas apresentam pouca variação geográfica em função do tempo.

A imagem Landsat 2 do ano de 1975 sensor MSS a ser registrada, implicou em dificuldades na edição do registro, devido ao fato de possuir baixa resolução espacial, apesar de ter sido reamostrada, de 80 × $80 \mathrm{~m}$ para $30 \times 30 \mathrm{~m}$ de resolução espacial. A reamostragem de Imagem foi necessária devido ao fato que a imagem base do registro possuir resolução espacial de 30 metros e a imagem a registrar possuir 80 metros de resolução, e ambas as imagens necessitam estarem na mesma resolução para não haver erros no registro bem como facilitar o estudo das lagoas. Optou-se pela reamostragem através do método da super-resolução, devido ao fato de se trabalhar com lagoas e a extensão espacial das mesmas ficarem melhores representadas na imagem Landsat 2 do ano de 1975 por este método.

A (Tab. 1) apresenta as coordenadas métricas dos pixels (Fig. 3) coletados na imagem base bem como da imagem a ser registrada. A última coluna representa o Erro Médio Quadrático RMS. É desejável que o RMS seja $<1$ pixel, isso porque 1 representa um pixel de 30 metros, ou seja, quando o RMS $<1$ significa que imagem não consegue identificar o erro, pois a resolução espacial da imagem não permite identificar alvos menores que $30 \mathrm{x}$ 30 metros, entretanto esta situação foi difícil de verificar devido à baixa resolução da imagem registrada.

\subsubsection{Redimensionamento da Cena}

Redimensionar a cena é necessário quando se realiza a análise multi-temporal de uma área relativamente pequena dentro de uma cena, o que facilita a sua análise. Com base (no limite municipal) efetuou-se o recorte, a área referente ao Município de Feira de Santana com o seguinte retângulo envolvente $39^{\circ} 5^{\prime}$ e $38^{\circ} 45^{\prime} \mathrm{W}$ e $12^{\circ}$ e $12^{\circ} 20^{\prime} \mathrm{S}$.

\subsubsection{Classificação de Imagens}

A classificação de imagens implica no processo de decisão, onde, o computador atribui conjuntos de pontos das imagens (pixels) a determinada classe temática. Os produtos desse processo são mapas temáticos correspondentes às classes de interesse, de acordo com critérios definidos. Logo, pode-se entender que a classificação de imagens constitui na transformação da imagem multiespectral em imagem sintética de classes temáticas. A classificação semi-automática tem a finalidade de agregar alvos que possuem assinaturas espectrais similares, sendo um processo de separação dos pontos (colunas e linhas) da matriz (imagem), em grupos de objetos geográficos, com características espectrais comuns (AGUIAR, 1993).

Neste trabalho, foi utilizado o algoritmo de classificação de máxima verossimilhança, este classificador possui habilidade de modelar distribuições das classes que são distribuídos em diferentes direções e comprimentos no espaço multiespectral. O algoritmo da máxima verossimilhança $(M A X V E R)$ consiste em atribuir um vetor à classe de maior densidade de probabilidade computada naquele ponto, estas classes são previamente adquiridas para treinar o classificador (RICHARDS; JIA, 2006).

O algoritmo MAXVER é estatístico-paramétrico, isto quer dizer que o algoritmo utiliza um modelo estatístico parametrizado pelas amostras de treinamento, admite-se para tanto, que a distribuição das amostras no espaço imagem é Gaussiana. Sabendo que os atributos $x_{j}$, $j=1, M$, são variáveis aleatórias, que constituem o vetor aleatório de observação $x$, supondo conhecidas (AGUIAR, 1993 JENSEN, 1995):

- $F\left(x / W_{i}\right):$ Função densidade de probabilidade associada à classe $W_{i}, i=1, \ldots$, $\mathrm{N}$; e $P\left(W_{i}\right)$ : probabilidade a priori de cada classe $W_{i}, i=1, \ldots N$.

- A fórmula bayesiana envolve custos de $C\left(W_{k} \mid W_{i}\right)$ : custo de tomar decisão por uma classe $\mathrm{W}_{\mathrm{k}}$ quando a verdadeira classe é $W_{i}$, i, $k=1, \ldots, N$.

Deste modo, observando o vetor $x$, o erro decorrente de tomar a decisão $W_{k}$ é (AGUIAR, 1993):

$$
L_{x}\left(W_{k}\right)=\sum_{i=1}^{n} C\left(W_{k} \mid W_{i}\right) P\left(W_{i} \mid X\right)
$$


Tabela 1 - Valores do pixel imagem base (Landsat 5/2008) e a imagem registrada (Landsat 2/1975)

\begin{tabular}{c|c|c|c|c|c|c}
\hline Pontos & Coordenadas dos pixels (metros) & $\begin{array}{c}\text { Imagem Base } \\
\text { (referencia) X }\end{array}$ & $\begin{array}{c}\text { Imagem } \\
\text { (referencia) } \\
\text { Base Y }\end{array}$ & $\begin{array}{c}\text { Imagem } \\
\text { Registrada X }\end{array}$ & $\begin{array}{c}\text { Imagem } \\
\text { Registrada } \\
\text { Y }\end{array}$ & RMS \\
\hline P1 & $\begin{array}{c}489764.90 \mathrm{E} \\
8660464.90 \mathrm{~N}\end{array}$ & 335.17 & 1245.50 & 749.25 & 1293.75 & 2.3418 \\
\hline P2 & $\begin{array}{c}497065.10 \mathrm{E} \\
8645005.00 \mathrm{~N}\end{array}$ & 91.83 & 730.17 & 506.25 & 778.50 & 3.5064 \\
\hline P3 & $\begin{array}{c}509534.90 \mathrm{E} \\
8645015.90 \mathrm{~N}\end{array}$ & 750.83 & 1245.17 & 1168.50 & 1296.00 & 1.3681 \\
\hline P4 & $\begin{array}{c}504221.90 \mathrm{E} \\
8667558.10 \mathrm{~N}\end{array}$ & 573.73 & 493.73 & 991.50 & 542.75 & 0.2445 \\
\hline P5 & $\begin{array}{c}489944.90 \mathrm{E} \\
8676919.90 \mathrm{~N}\end{array}$ & 97.83 & 181.67 & 502.50 & 227.50 & 1.7615 \\
\hline P6 & $\begin{array}{c}500840.00 \mathrm{E} \\
8636627.50 \mathrm{~N}\end{array}$ & 461.00 & 1524.74 & 877.33 & 1573.00 & 0.9327 \\
\hline
\end{tabular}

Deve-se tomar a decisão $W_{k}$ que reduza o erro médio sobre a distribuição de $x$, ou seja (AGUIAR, 1993),

$$
L_{x}\left(W_{k}\right)=\int_{x} L_{x}\left(W_{k}\right) f(x) d x
$$

$L\left(W_{k}\right)$ constitui-se no minimizador, para cada valor de $x, L_{x}\left(W_{k}\right)$ seja minimizado.

Considerado os custos $C\left(W_{k} \mid W_{i}\right)$ da forma $C\left(W_{k} \mid W_{i}\right)=0$, se $i=k$, e $C\left(W_{k \mid} W_{i}\right)=1$, se $i \neq k$, onde $i, k=1, \ldots$ $N$, a expressão torna-se:

$$
L_{x}\left(W_{k}\right)=1-P\left(W_{k} \mid x\right)
$$

Desta maneira, o processo de classificação pode ser encarado como o cálculo de função discriminante (AGUIAR, 1993)

$$
P\left(W_{k} \mid x\right)=\frac{f\left(x \mid W_{k}\right) P\left(W_{k}\right)}{f(x)}
$$

Como o denominador é independente de $k$, pode-se atribuir o vetor $x$ a classe que maximize a expressão $f\left(x / W_{k}\right) P\left(W_{k}\right)$,

$$
G(x)=P\left(W_{k} \mid x\right) P\left(W_{k}\right), \text { com } i=1 \ldots n
$$

Para cada vetor de atributos $x$ observado, de forma que vetor $x$ seja classificado como pertencente à classe $W_{k}$ que forneça a máxima função discriminante.

Logo, ao minimizar $L_{x}\left(W_{k}\right)$ se obtém para cada vetor $x$ de atributos (pixels) observados, decide-se para cada classe $W_{k}$ que maximize a probabilidade a posteriori $P\left(W_{k} / x\right)$.
O algoritmo MAXVER é um modelo supervisionado, pois na sua fase inicial é fornecido o número de classes e as áreas de treinamento de cada classe. Sendo assim, o algoritmo $M A X V E R$ associa o pixel à classe qual tenha maior probabilidade de pertencer, tendendo a minimizar a probabilidade de erro, ou seja, a possibilidade de certo pixel esteja associado à classe que ele realmente não pertença.

Para avaliar a precisão das amostras foi utilizado o índice de separabilidade de (Jeffries-Matusita, Transformed Divergence). Neste índice os valores variam de 0 a 2 , sendo os valores próximos a 0 representam a separação mínima entre as classes, valores próximos de 2 representam auto índice de separabilidade entre classes. $\mathrm{O}$ índice de separabilidade Jeffries-Matusita pode ser calculado a partir da expressão (RICHARDS; JIA, 2006):

$$
J M=\sqrt{2\left(1-e^{\phi}\right)}
$$

$$
\begin{aligned}
& \phi=\frac{1}{8}\left(\mu_{i}-\mu_{j}\right)^{T}\left(\frac{\sum X_{i}+\sum X_{j}}{2}\right)^{-1}\left(\mu_{i}-\mu_{j}\right)+ \\
& +\frac{1}{2} \ln \left[\frac{0,5\left|\sum X_{i}+\sum X_{j}\right|}{\sqrt{\left|\sum X_{i}\right|+\left|\sum X_{j}\right|}}\right]
\end{aligned}
$$

onde, $i$ e $j$ são duas distribuições, $\Sigma_{\mathrm{i}} \in \Sigma_{j}$ das matrizes de covariância de $i$ e $j$ respectivamente e, $\mu_{i}$ e $\mu_{j}$ são as médias de cada distribuição. A divergência transformada pode ser calculada pela expressão a seguir: (RICHARDS; JIA, 2006):

$$
D T_{i j}=a\left(1-\exp \left(\frac{D_{i j}}{b}\right)\right)
$$


Sendo $a$ e $b$ constantes escolhidas pelo usuário para $a$ avaliação de $D T$ a divergência

\section{ANÁLISE DOS RESULTADOS}

\subsection{Separabilidade Entre Classes}

A escolha das classes na classificação supervisionada é uma etapa importante, pois com base nestas classes, o algoritmo realizará a classificação. Para escolher as classes devem ser considerados alguns aspectos: trabalho de campo, resolução da imagem de satélite e objetivo do trabalho. Com base nessas informações para a imagem Landsat 2 do ano de 1975 foram delimitadas as seguintes classes temáticas: Vegetação Rasteira; Vegetação Arbórea; Solo Exposto; Área Urbana; Água, Nuvem e Sombra de Nuvem. Para a imagem Landsat 5 do ano de 2008 foram adotadas as classes: Água, Solo Exposto, Vegetação Aquática, Vegetação Rasteira, Vegetação Densa, Nuvem, Sombra de Nuvem, Densamente Povoado e Povoado. Ressaltando que a classe Vegetação Aquática foi incorporada à classe Vegetação e Área Urbana foi subdividida em Densamente Povoado e Povoado.

Para a imagem Landsat 2 de 1975 os valores de Jeffries-Matusita e divergência transformada que tiveram pior resultado foram Vegetação Rasteira e Vegetação Densa. A separabilidade entre Vegetação Rasteira e Vegetação Densa foi pequena: 1,1 para Jeffries-Matusita e 1,6 para Divergência transformada. Porém, estes valores foram previstos uma vez que ambas as classes tratam de vegetação que possuem comportamento espectral similar, além disso, a vegetação densa não é muito arbustiva sendo que perde suas folhas durante o período de seca. Ocorreu confusão entre Água e Sombra de Nuvem, pois ambos possuem seus níveis de cinza muito baixos por isso os valores de Jeffries-Matusita e Divergência Transformada foram ambos de 1,2. Foi verificado também confusão entre as classes Solo Exposto e Urbano, no entanto, essa confusão dá-se devido à existência de solo exposto no perímetro urbano, além da variação do índice de reflectância das áreas urbanas os valores de Jeffries-Matusita e Divergência transformada ficaram em 1,5 em ambos, as demais classes não apresentaram confusões significativas tendo seus valores de JeffriesMatusita e Divergência Transformada variando entre 1,8 a 2,0 , respectivamente.

Considerando a imagem Landsat 5 de 2008 as suas classes tiveram o seguinte desempenho. A maior confusão entre classes foi classe Povoada e Densamente Povoada, onde os valores de Jeffries-Matusita e Divergência transformada ficaram em 1,4 e 1,5 respectivamente - essa confusão era esperada uma vez que a classe estudada era o urbano heterogêneo por natureza apresentando grande similaridade na sua resposta espectral. Os demais valores para Jeffries-Matusita tiveram desempenho satisfatório variando entre 1,8 a 2,0 para Jeffries-Matusita e 1,9 e 2,0 para a divergência transformada.

\subsection{Classificação das Imagens.}

Para a classificação da imagem utilizou-se o algoritmo supervisionado de Máxima Verossimilhança $(M A X V E R)$. Este classificador usa como parâmetros os pixels de treinamento, que correspondem às classes analisadas anteriormente. Na análise visual das imagens classificadas Landsat 2 do ano de 1975 (Fig. 4) e da imagem Landsat 5 do ano de 2008 (Fig. 5), verifica-se a qualidade da classificação, pois as classes ficaram bem separadas, sendo possível identificar cada classe adotada.

Para a avaliação da precisão da classificação foram adotados os seguintes modelos matemáticos: o índice Kappa e matriz de confusão com a apresentação dos valores em porcentagem. O índice Kappa $(\mathrm{K})$ mede o grau de concordância da classificação digital com o encontrado em campo (SCHOWENGERDT, 2007).

$\mathrm{O}$ resultado da Eq. 10 pode ser comparado com a tabela a seguir que indica o grau de concordância.

Com base na (Tab.2) e sabendo que o coeficiente Kappa foi de: 0.90, para a imagem Landsat 2 do ano 1975 pode-se considerar a classificação com o algoritmo MAXVER como adequada de acordo com Galparsoro e Fernández (2001). Além do índice Kappa também foi utilizado a matriz de erros em porcentagem para avaliar a classificação da imagem Landsat 2 do ano de 1975 (Tab. 3). A escolha da matriz de erros em porcentagem foi adotada devido às discrepâncias entre a quantidade de pixel coletados nas diferentes classes temáticas.

Com base na matriz de erros é possível diagnosticar a classificação como satisfatória, uma vez que, os pixels que houve confusão de classes ficaram dentro do esperado, por exemplo, há confusão entre água e sombra de nuvem sendo que $8,32 \%$ dos pixels água foram classificados como sombra de nuvem.

Porém a classe temática que mais ocorreu confusão foi vegetação densa e vegetação rasteira onde $19,02 \%$ dos pixels referente à vegetação densa foram classificados como vegetação rasteira, isso ocorre devido à proximidade do comprimento de onda no índice de reflectância.

Tabela 2 - Grau de concordância do Kappa

\begin{tabular}{c|c|c}
\hline \multicolumn{2}{c|}{ Valor do Kappa } & Concordância \\
\hline$<$ & 0,20 & Pobre \\
\hline 0,21 & 0,40 & Fraca \\
\hline 0,41 & 0,60 & Moderada \\
\hline 0,61 & 0,80 & Boa \\
\hline 0,81 & 1,00 & Muito boa \\
\hline
\end{tabular}

Fonte: adaptado de Schowengerdt (2007)

O valor do índice Kappa para a imagem Landsat 5 de 2008 revela a qualidade da classificação, sendo que para esta imagem, o valor ficou em 0,94 que de acordo com a (Tab. 2) avalia como muito boa esta classificação. 
Analisando a matriz de erros (Tab. 4) percebe-se que a classe Povoado possui maior confusão com as demais, principalmente com a classe Densamente Povoado. Este resultado era previsto, pois há grande heterogeneidade do índice de reflectância para classe urbano, ressaltando que
A tabela 3 mostra a matriz de erros para a época 1975 na situação de caracterização inicial como mostrada na fig. 4.

Tabela 3 - Refere-se à matriz de erros em porcentagem para a imagem Landsat 21975

\begin{tabular}{l|l|l|l|l|l|l|l|l}
\hline \multicolumn{1}{c|}{ Classes } & Água & Nuvem & $\begin{array}{l}\text { Sombra de } \\
\text { Nuvem }\end{array}$ & $\begin{array}{c}\text { Vegetação } \\
\text { Densa }\end{array}$ & $\begin{array}{l}\text { Vegetação } \\
\text { Rasteira }\end{array}$ & $\begin{array}{c}\text { Solo } \\
\text { Exposto }\end{array}$ & $\begin{array}{c}\text { Area } \\
\text { Urbana }\end{array}$ & Total \\
\hline Água & 91.46 & 0.00 & 8.53 & 0.00 & 0.00 & 0.00 & 0.00 & 13.21 \\
\hline Nuvem & 0.00 & 100 & 0.00 & 0.00 & 0.00 & 0.00 & 0.00 & 15.90 \\
\hline $\begin{array}{l}\text { Sombra de } \\
\text { Nuvem }\end{array}$ & 8.32 & 0.00 & 91.47 & 0.00 & 0.00 & 0.00 & 0.00 & 14.83 \\
\hline $\begin{array}{l}\text { Vegetação } \\
\text { Densa }\end{array}$ & 0.00 & 0.00 & 0.00 & 80.08 & 7.31 & 0.00 & 0.00 & 12.70 \\
\hline $\begin{array}{l}\text { Vegetação } \\
\text { Rasteira }\end{array}$ & 0.00 & 0.00 & 0.00 & 19.92 & 92.61 & 0.00 & 0.00 & 18.73 \\
\hline $\begin{array}{l}\text { Solo Exposto } \\
\text { Área Urbana }\end{array}$ & 0.00 & 0.00 & 0.00 & 0.00 & 0.08 & 96.48 & 6.84 & 13.74 \\
\hline Total & 100. & 100 & 100 & 100 & 100 & 100 & 100 & 100.00 \\
\hline
\end{tabular}

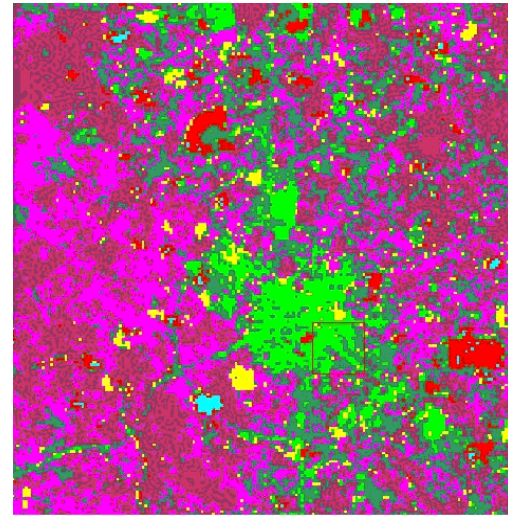

Imagem Classificada do Município de Feira de Santana

Figura 4 - Imagem Landsat 2 de 1975 classificada pelo MAXVER.

Comparando os resultados obtidos nas imagens classificadas é possível inferir que o avanço do espaço urbano sobre as lagoas vem causando variados desequilíbrios ambientais (Fig. 4 e 5).

$\mathrm{Na}$ área referente à lagoa da Tabua (Fig. 6) é possível identificar presença de lamina d'água na imagem de 1975 , isso não acontece na imagem de 2008, pois na lagoa da Tabua a cobertura de solo se modifica em solo exposto. Nas margens desta lagoa ocorrem a presença de vegetação rasteira e resquícios de vegetação densa, e com a existência pequena de área urbana, no entanto na imagem de 2008 há uma mudança drástica na cobertura do solo, pois o mesmo se transforma em área povoada. Essa mudança da cobertura de solo reflete na lagoa sedimentando a mesma dificultando a mesma de reter água o que justifica a sua transformação em solo exposto tanto a classe. Densamente Povoado como a Povoado são subcategorias da classe Urbano.

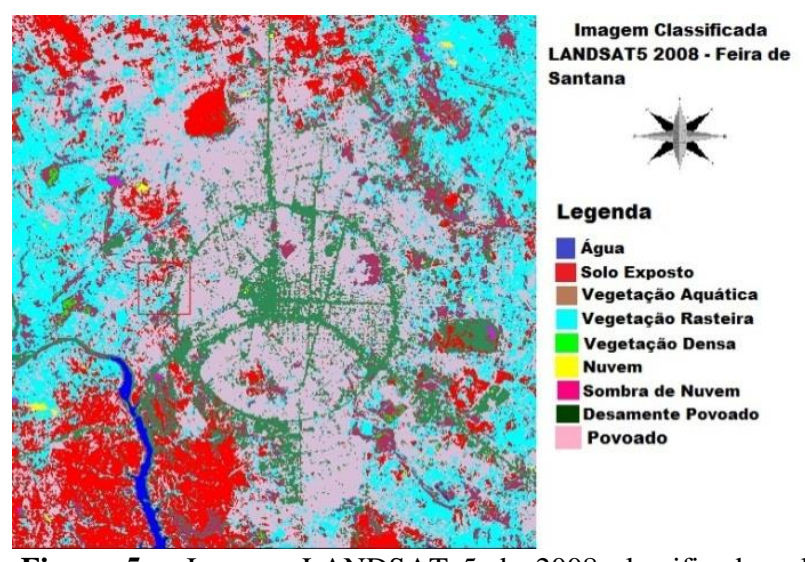

Figura 5 - Imagem LANDSAT 5 de 2008 classificada pelo MAXVER nota-se que a Lagoa da Tabua está classificada como solo exposto.

Na área referente à Lagoa Grande (Fig. 7) as transformações da cobertura de solo foram mais acentuadas. Embora, no ano de 1975 ocorrem algumas ocupações no entorno desta lagoa, no ano de 2008 as margens deste recurso hídrico são completamente transformadas em área povoada. Outro fator que serve de indicador para esta lagoa é a presença de vegetação aquática (Taboa) em abundância, este tipo de vegetação é comum em áreas muito poluídas. 

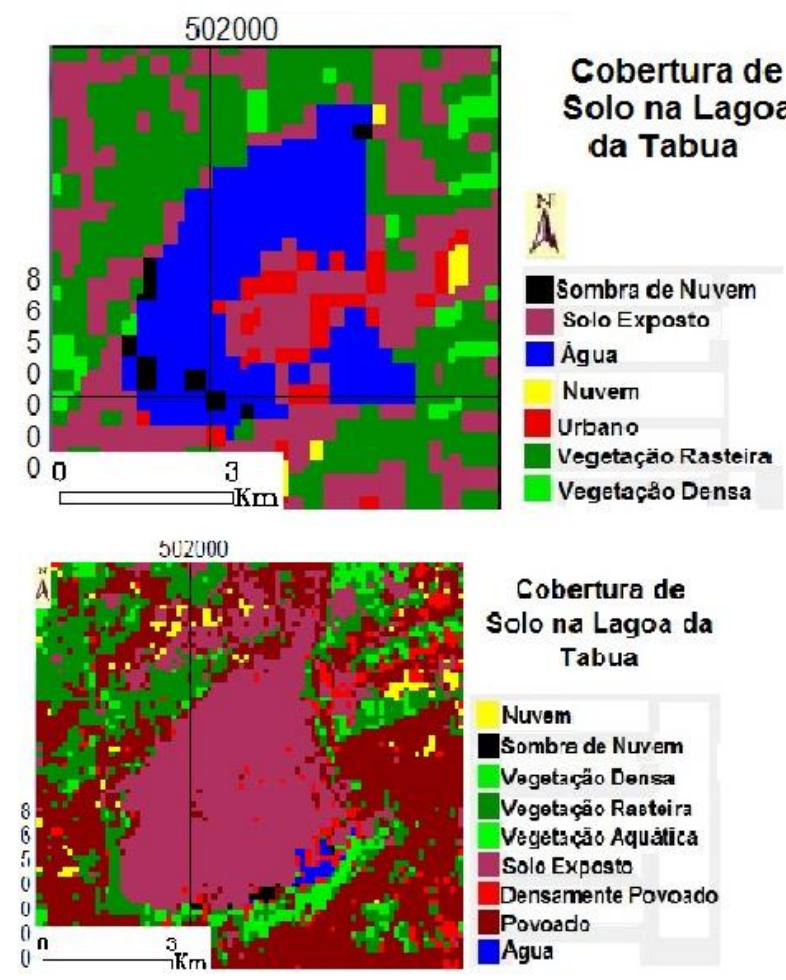

\section{Cobertura de \\ Solo na Lagoa da Tabua}

\section{Nuvem}

Sombre de Nuvem Vegetaçäa Densa Vogotaçä Raeteira Vegetasuso Aquätica Solo Expesto

Densamente Povoado Povoado Agua

Figura 6 - Cobertura de solo na Lagoa da Tabua entre os anos de 1975 e 2008.

Embora já exista o avanço do espaço urbano nas lagoas urbanas a classe área urbana corresponde a apenas $1,6 \%$ a classe água é de $1,1 \%$ destaca-se a classe vegetação aquática com $11,6 \%$ sabendo que este tipo de vegetação é indicativo de poluição.

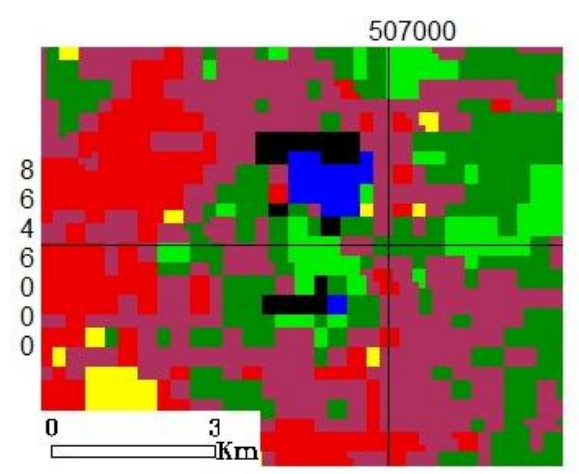

Cobertura de Solo na Lagoa

A Grande
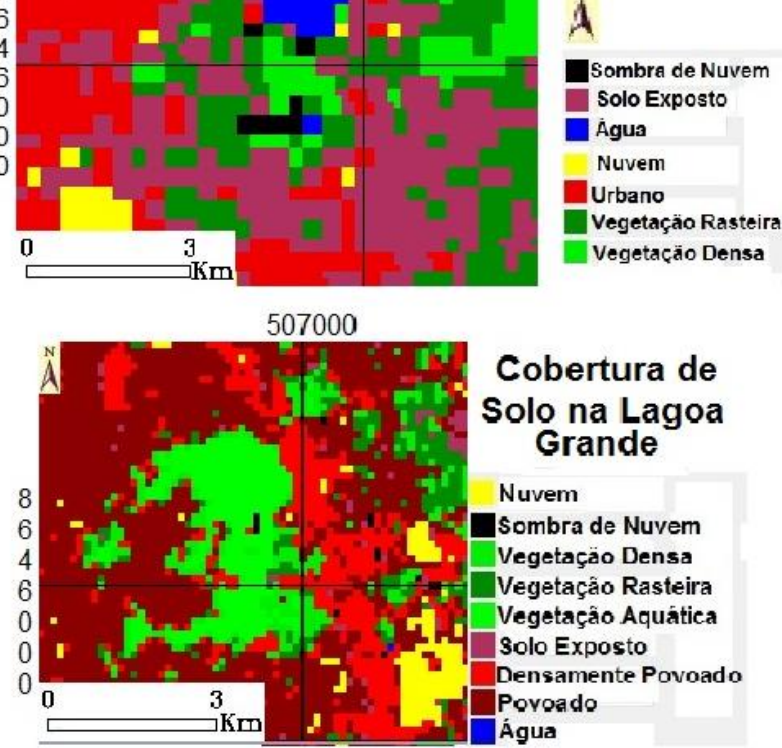

Figura 7 - Cobertura de solo na Lagoa Grande entre os anos de 1975 e 2008.

$\mathrm{Na}$ imagem estudada a classe que teve maior representatividade foi vegetação densa com 30,9\% e vegetação rasteira com $27,0 \%$ estes valores eram esperados, pois o período analisado corresponde ao início transição entre um município rural, com vocação para agropecuária, para uma cidade industrializada, mas ainda existindo grandes pastagens.

Tabela 4 - Refere-se à matriz de erros em porcentagem para a imagem Landsat 21975

\begin{tabular}{|c|c|c|c|c|c|c|c|c|c|c|}
\hline Classes & Água & $\begin{array}{l}\text { Solo } \\
\text { Exposto }\end{array}$ & $\begin{array}{l}\text { Vegetação } \\
\text { aquática }\end{array}$ & $\begin{array}{l}\text { Vegetação } \\
\text { rasteira }\end{array}$ & $\begin{array}{l}\text { Vegetação } \\
\text { densa }\end{array}$ & Nuvem & $\begin{array}{l}\text { Sombra } \\
\text { de } \\
\text { nuvem }\end{array}$ & $\begin{array}{l}\text { Densamente } \\
\text { povoado }\end{array}$ & Povoado & Total \\
\hline Água & 97.79 & 0.0 & 0.0 & 0.0 & 0.0 & 0.0 & 0.0 & 0.0 & 0.0 & 14.18 \\
\hline Solo Exposto & 0.0 & 97.84 & 0.0 & 0.14 & 0.0 & 0.0 & 0.0 & 1.08 & 0.72 & 20.84 \\
\hline $\begin{array}{l}\text { Vegetação } \\
\text { aquática }\end{array}$ & 0.0 & 0.0 & 86.28 & 0.57 & 1.39 & 0.0 & 0.0 & 0.0 & 0.72 & 7.77 \\
\hline $\begin{array}{l}\text { Vegetação } \\
\text { rasteira }\end{array}$ & 0.0 & 0.0 & 4.57 & 98.3 & 0.0 & 0.0 & 0.0 & 0.0 & 2.77 & 12.49 \\
\hline $\begin{array}{l}\text { Vegetação } \\
\text { densa }\end{array}$ & 0.0 & 0.0 & 6.76 & 0.0 & 98.61 & 0.0 & 0.0 & 0.0 & 0.0 & 16.10 \\
\hline Nuvem & 0.0 & 0.0 & 0.0 & 0.0 & 0.0 & 100 & 0.0 & 0.0 & 0.12 & 2.93 \\
\hline $\begin{array}{l}\text { Sombra de } \\
\text { nuvem }\end{array}$ & 0.0 & 0.0 & 0.0 & 0.0 & 0.0 & 0.0 & 100 & 0.0 & 0.0 & 5.11 \\
\hline $\begin{array}{l}\text { Densamente } \\
\text { povoado }\end{array}$ & 1.74 & 1.6 & 0.99 & 0.0 & 0.0 & 0.0 & 0.0 & 86.99 & 4.34 & 6.69 \\
\hline Povoado & 0.0 & 0.56 & 1.39 & 0.99 & 0.0 & 0.0 & 0.0 & 11.92 & 91.33 & 13.88 \\
\hline Total & 100 & 100 & 100. & 100 & 100 & 100 & 100 & 100 & 100 & 100.00 \\
\hline
\end{tabular}




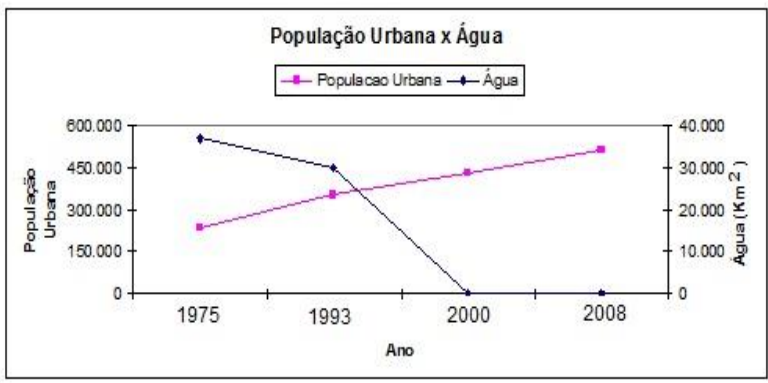

Figura 8 - Refere-se ao gráfico de crescimento da população urbana e da classe água superficial em função do tempo.

Fonte: senso populacional IBGE

O gráfico da Fig. 8 mostra o crescimento da população urbana em função do tempo bem como redução de aquíferos dentro do perímetro urbano em função do tempo. Permite generalizar que o crescimento urbano não respeitou os limites impostos pela natureza, transformando a água em espaço urbano ou solo exposto. Ressalta-se que na construção do gráfico não se levou em consideração eventos de chuvas no período de aquisição das imagens. No entanto todas as imagens são adquiridas em um período climático de deficiência hídrica. Sendo assim a redução dos corpos d'água no perímetro urbano de Feira de Santana é mais consequência do avanço da população sobre os recursos hídricos do que da ausência de chuva.

A inexistência de água nas lagoas, devido alto grau de impacto ambiental, impossibilita uma análise química das águas. No entanto, é possível classificar os impactos ambientais nas lagoas dedutivamente a partir das imagens Landsat classificadas, e dos processos de impacto ambiental descritos anteriormente, propõe-se uma escala de degradação para as lagoas estudadas.

A escala proposta varia de 00 a $100(\%)$. Onde zero representa a ausência total de poluição e 100 corresponde à extinção total do recurso hídrico, ou seja, 100\% degradado, conforme a tabela (Tab. 5) a seguir, ressalta-se que a tabela foi construída a partir de dedução lógica:

Tabela 5 - Escala de degradação definida no trabalho

\begin{tabular}{|cl|}
\hline Escala (\%) & \multicolumn{1}{c|}{ Impacto ambiental } \\
\hline 0 a 25 & $\begin{array}{l}\text { Presença de Produtos químicos e sedimentos em } \\
\text { suspenção. Primeiras ocupações urbanas no entorno. }\end{array}$ \\
\hline 25 a 50 & $\begin{array}{l}\text { Retirada da vegetação do entorno; produtos } \\
\text { químicos diluídos, surgimento de solo exposto. }\end{array}$ \\
\hline 50 a 75 & $\begin{array}{l}\text { Substituição da vegetação ciliar por área } \\
\text { adensamento urbano; assoreamento do leito e morte } \\
\text { da fauna aquática. }\end{array}$ \\
\hline 75 a 100 & $\begin{array}{l}\text { Invasão do leito da lagoa por construções urbanas; } \\
\text { dificuldade da lagoa em reter agua; mau cheiro dos } \\
\text { esgotos. }\end{array}$ \\
\hline
\end{tabular}

Do cruzamento da escala de degradação com os mapas temáticos foi detectado um estágio inicial em 1975 onde na Lagoa Grande em 1975, estima-se degradação de
25 a $50 \%$ e de 0 a 25\% para a Lagoa Tabua (Fig. 9). De 1975 a 1993 o processo de degradação da Lagoa Grande e da Lagoa Tabua é acentuado restando apenas alguns pontos dentro da lagoa com água. $\mathrm{O}$ entorno sofre $\mathrm{o}$ processo de adensamento considerável, outro fator marcante é a presença crescente da vegetação aquática, porém essa vegetação é a Taboa indicadora de poluição. O percentual estimado de degradação para as lagoas sobe respectivamente para o nível de 50 a $75 \%$ para a lagoa Grande e 25 a 50\% para a lagoa Tabua em 1993.

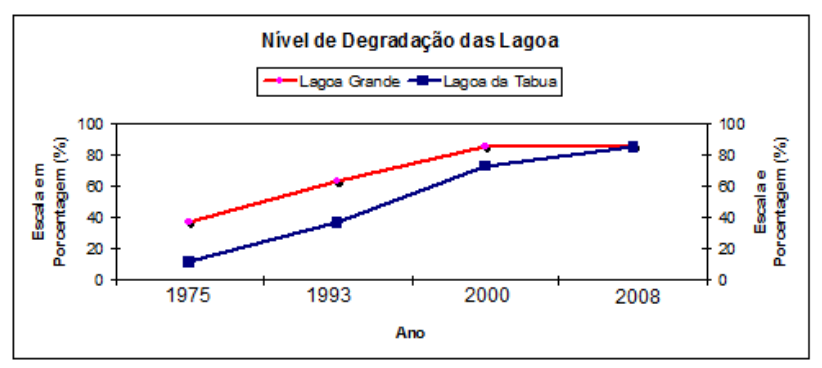

Figura 9 - Estimativa em porcentagem do nível de degradação da Lagoa Grande e Lagoa da Tabua.

No ano 2000 há uma enorme heterogeneidade quanto a classificação da imagem, isto indica o alto grau da ação antrópica sobre as lagoas. Entre as classes adotadas no estudo, a que tem maior representatividade nesta cena e a densamente povoado e povoado, restando alguns resquícios de vegetação, no entanto esta vegetação não é original da região mas sim uma vegetação invasora, que aproveitando-se da umidade inerente a região começa a ocupar espaço. Não se observa nesta imagem a existência de água, mesmo a lagoa Grande sendo nascente do Rio Subaé. Pode-se inferir uma degradação de 75 a $100 \%$ para ambas as lagoas em 2000. Apesar de ser possível classificar a degradação de ambas as lagoas em 2008 está entre 75 a 100\% do nível de degradação, as mesmas não atingiram o mesmo nível simultaneamente. A lagoa Grande teve seu processo degenerativo mais acelerado que a Lagoa da Tabua, isto porque a Lagoa Grande encontra-se mais próximo do centro comercial de Feira de Santana. No entanto, com a expansão urbana teve maior intensidade a partir do ano 2000 na região da Lagoa da Tabua, sendo que embora o alto grau de degradação atingida por esta lagoa, com a dificuldade de reter água, assoreamento da lagoa, morte da vida aquática, e adensamento populacional das margens, a mesma ainda tem resquícios de água e vegetação densa, isso devido à região ser nascente do Rio Pojuca e seu processo de degradação ambiental não ser tão acelerado quanto o ocorrido na Lagoa Grande.

\section{CONSIDERAÇÕES FINAIS}

Os estudos multitemporais que utilizam sensoriamento remoto necessitam de vários cuidados para que os mesmos minimizem a influência das incertezas inerentes ao correlacionamento estabelecido entre a variável analisada e a imagem ou mapa temático. Avaliando a separabilidade entre classes bem como o 
índice Kappa conclui-se que esta metodologia é bastante eficaz para estudos ambientais.

Foi possível, através desta metodologia, identificar alguns indicadores de desequilíbrio ambiental, como por exemplo, o avanço do espaço urbano implicando sedimentação da Lagoa da Tabua, e na presença de Taboa, vegetação aquática comum em áreas muito poluídas na Lagoa Grande. Foi possível perceber evoluções distintas nas lagoas analisadas, para tanto a definição de uma escala de degradação foi crucial. A diferença na evolução está associada a velocidade de interferência humana e as condições naturais de formação do ambiente estudado. De posse dessas informações revela-se a trajetória que levam as lagoas estudadas a um quadro de assoreamento, as margens encontram-se bastante urbanizadas, e o leito das lagoas é receptáculo de lixo e entulho, esgotos domésticos entre diversos outros tipos de materiais poluidores. As condições de vida da população que moram nesta região são sub-humanas, a população que reside no entorno destas lagoas convive sem rede de esgotamento sanitário, em épocas de chuvas as aguas invadem as casas, lixo e material fecal espalhado por toda a região, sendo, portanto vetor de diversas doenças.

Não se pretende com este trabalho esgotar as possibilidades de pesquisa, ou limitar metodologias, mas, ampliar a discussão sobre a degradação dos recursos hídricos. Ressaltando que este trabalho é parte de uma dissertação de mestrado que estuda o avanço do espaço urbano sobre a Lagoa da Tabua e Lagoa Grande com técnicas de sensoriamento remoto. Dentro dessa perspectiva pode-se com agregação de inferências diretas, melhorar a acurácia dos resultados e de uma classificação que leve em consideração o nível de degradação de ambientes naturais que sofram pressões antrópicas.

\section{REFERÊNCIAS BIBLIOGRÁFICAS}

AGUIAR, A. P. D. Utilização de atributos derivados de proporções de classes dentro de um elemento de resolução de imagem (Pixel) na classificação multiespectral de imagens de sensoriamento remoto. Dissertação de Mestrado - São José dos Campos: INPE- 1993

ALIXANDRINI, M. J. Jr. Methodology for land cover change study with historical remote sensing Data set: case Itaipu region. PHD Thesis. Karlsruhe Institute of Technology. Germany. 2010.

CRÓSTA, Á. P. 1993 Processamento Digital de Imagens de Sensoriamento Remoto, Campinas, IG/Unicamp. 1993.

FERNANDES, V. de O.; ALIXANDRINI JUNIOR, M. J.; CARVALHO, M. A.. Análise da influência ambiental de pedreiras localizadas em áreas urbanas a partir da classificação de imagens multitemporais. In: XV Simpósio Brasileiro de Sensoriamento Remoto, 2011, Curitiba. XV Simpósio Brasileiro de Sensoriamento Remoto, 2011.
JENSEN, J. R. Introductory digital Image processing: a remote sensing perspective. $2^{\circ}$ ed. New Jersey Prentice Hall, 316 p. 1996.

LILLESAND, T. M.; KIEFER, R. W. Remote Sensing and image interpretation. $4^{\text {th }}$ ed. Ed John Wiley $\mathrm{e}$ Sons. 724p. 2000.

MATHER, P. M. Computer Processing of remotely sensed images. Chichester: J. Wiley,. 352 p. 1987

MILlER JR., G. T. Ciência ambiental. São Paulo: Thomson, 2007. 501 p. 2007.

PHILLIPS, T. L.; SWAIN, T. H. Data processing methods and systems. In: SWAIN, P. H.; DAVIS, S. 1988.

RICHARDS, J. A., e JIA, X. Remote sensing digital image analysis. Springer. 2006.

RICHARDS, J. A. Remote sensing digital image analysis: an introduction. 2nd, rev. and enl. ed Berlin: SpringerVerlag, 1993.

SCHOWENGERDT, R. A. Remote Sensing: models and methods for image processing. 3. ed. Amsterdam: Elsevier. 2007. 